\title{
Cardiac Arrest/Arrhythmia Etiology Unknown
}

National Cancer Institute

\section{Source}

National Cancer Institute. Cardiac Arrest/Arrhythmia Etiology Unknown. NCI Thesaurus.

Code C100033.

An episode of cardiac arrest or arrhythmia where the etiology was unknown. (ACC) 